\title{
Kasuistik
}

Alexander Bischoff*

\section{Das Aushandeln von Sinn - über interkulturelle Kommunikation und Spiritualität}

https://doi.org/10.1515/spircare-2019-0063

Ich habe die Sprechstunde noch in lebhafter Erinnerung:

Frau Inês - nennen wir sie so - ist Angolanerin; sie spricht Kikongo und Portugiesisch. Die Kommunikation kommt nur langsam in Gang. Mit von der Partie sind noch: Der Arzt, Genfer, spezialisiert für Gewaltopfer und posttraumatischen Stress, und ich als Pflegeexperte und (heute) als Ad-hoc-Dolmetscher. Die Sprechstunde findet im Rahmen der „Visite sanitaire“ der Asylsuchenden im Kanton Genf statt.

Frau Inês klagt im Verlauf des Gespräches wiederholt über drei Dinge:

A cabeça está quente aí em cima no meio. Der Kopf ist heiß hier oben in der Mitte.

Às vezes está a estalar. Manchmal zerspringt er.

Os seios vão cair. Die Brüste werden abfallen.

Inês erwähnt diese merkwürdigen Beschwerden im Verlauf des Arztgesprächs. Weil die Kikongo-Dolmetscherin nicht rechtzeitig organisiert werden konnte, bin ich auf Anfrage des Arztes eingesprungen und dolmetsche nun Französisch-Portugiesisch. Inês stammt aus dem Norden Angolas, sie ist eine Bakongo aus Uíge. Sie ist vor dem Bürgerkrieg geflohen.

Der Kopf ist heiß in der Mitte, sie zeigt genau wo. Manchmal explodiert der Kopf. Sie braucht das Wort estalar, das Verb, das meist im Zusammenhang mit Minen gebraucht wird (und davon ist oft die Rede in Angola, dem Land der zahllosen Minenlegerfraktionen). Im Gespräch und im Dolmetschen wird nach und nach klar, dass es ein vordringliches und ein hintergründiges, aber schwerer wiegendes Problem gibt. Das vordringliche ist die Schlaflosigkeit, die Albträume und das Kopfweh. Dieses Kopfweh ist weniger im Sinn von Migränen und Kopfschmerzen zu verstehen, sondern als Belastung des Kopfes; zu viel geht da vor sich, zu viel ist drin an Sorgen und Belastungen. Der Kopf platzt fast, está a estalar. Sie braucht Beruhigungsmittel.

*Korrespondenzautor: Alexander Bischoff, Fribourg (Schweiz), E-Mail: alexander.bischoff@hefr.ch
Dann es geht um tieferliegende Schmerzen. Os seios vão cair, erwähnt sie mehrmals, in verschiedenen Variationen. Das klingt so mysteriös. Die Brüste werden fallen, werden abfallen. Die wörtliche Übersetzung ist zuerst einmal wichtig, aber dann bei weitem nicht genug. Der Arzt hat seine Jugend in Südafrika verbracht. Er ist hellhörig für diese Art Formulierungen, kennt verschiedene Kontexte, interessiert sich für ähnliche, aber doch fremde kulturelle Kontexte. Wir fragen weiter. Zu dritt suchen wir den Sinn. Wir handeln Bedeutungen aus. Ich kenne den Kontext aus der Bakongo-Tradition, kenne die Region.

Was wir zu dritt tun, ist Aushandeln. Von Joseph Kaufert, einem amerikanisch-kanadischen Anthropologen, der grundlegende Arbeiten zur kulturellen Mediation bei den Aborigines im hohen Norden Kanadas durchgeführt hat, stammt der treffende Ausdruck ,the negotiation von meaning“, das Aushandeln von Sinn (Kaufert 1999). Zuerst geht es um das Aushandeln zwischen zwei Systemen. Arthur Kleinman hat das schön herausgearbeitet (Kleinman et al. 1978). Jede medizinische Interaktion ist ein Aushandeln zwischen den beiden Perspektiven Disease und Illness: Jede medizinische und pflegerische Interaktion (ob mit oder ohne „Fremdheitsfaktor“, d. h. sprachlichen oder kulturellen oder religiösen Barrieren) ist ein Aushandeln zwischen zwei Systemen, dem Disease-System und dem Illness-System. Da ist auf der einen Seite die Krankheit (Disease) und auf der anderen das Kranksein (Illness), auf der einen Seite die medizinische Sichtweise (objektive, wissenschaftlich, messbar, dualistisch), auf der anderen die subjektive Sichtweise, die erlebte, ungeteilte, ganzheitliche. Das Disease-System schaut auf das, was ein Organ hat, und versucht einen biologischen oder psychologischen Schaden zu beheben. Das Illness-System schaut nicht auf das Organ, sondern auf den Menschen, und dazu den Menschen in seinem Umfeld. Die Illness-Seite fragt nach dem Sinn des Erfahrenen und der Krankheit. (Mehr dazu in Kleinman 1978; Helman 2000; Weiss 2003; Domenig 2007).

Wenn zu dritt ausgehandelt werden muss, wird natürlich alles komplizierter. Joseph Kaufert spricht im Fall einer medizinischen Interaktion zu dritt, d. h. wenn eine dolmetschende Person dabei, vom Aushandeln von Sinn. 
Und die dolmetschende Person nennt er gelegentlich cultural broker, einen „kulturellen Makler“ (Kaufert \& Koolage 1984; Kaufert \& Putsch 1997) .

Wir - Inês, der Arzt, und ich als Dolmetschender handeln zwischen Disease und Illness den Sinn der Krankheit aus und kommen $\mathrm{zu}$ folgendem Verhandlungsergebnis:

Wir können zu dritt den Fluch - denn darum handelt es sich - auslegen. Ein Mann muss ihr diese Drohung ausgesprochen haben, als sie auf der Flucht war in jenen Jahren der zahllosen Frontlinien-Verschiebungen in dem mehr als dreißigjährigen Krieg in Angola. „Deine Brüste werden abfallen": Das war eine Attacke auf das Frausein, auf die Fähigkeit des Mutterseins, das sie nach Jahren immer noch quälte. Das Gespräch entwickelt sich weiter zu einer Diskussion über spirituelle Fragen: Feitiço (Zauberei) und die kleinen und großen Zauberer, Leute, die in sich in einem magischen Denksystem bewegen, und im angolanischen Leben als Kimbandeiros und Kimbandeiras durchaus präsent sind.

Dass das kleine Kind in der Sprechstunde dabei war, war eine Antwort darauf, dass Inês nicht mehr unter dem Bann jener Angst stehen musste, und daher voll Frau und voll Mutter war, nicht eine eingeschränkte, unvollständige, bei der die Brüste abgefallen waren. Der Arzt sagte: Schauen Sie doch: Sie sind nicht mehr unter dem Fluch, denn Sie sind Mutter, sie haben ein kleines, gesundes Mädchen. Inês strahlte, als wir auf das kleine Mädchen zu sprechen kamen, und der große Mutterstolz war offensichtlich. Mit dieser Interpretation fand der Trialog zu einem Ende.

\section{Literaturangaben}

Domenig D (2007) Transkulturelle Kompetenz. Lehrbuch für Pflege-, Gesundheits- und Sozialberufe. Bern: Hans Huber Verlag. Helman CG (2000) Culture, Health and Illness (4. Aufl.). Oxford: Butterworth-Heinemann.

Kaufert JM (1999) Cultural mediation in cancer diagnosis and end of life decision-making: the experience of Aboriginal patients in Canada. Anthropology \& Medicine 6:405-421.

Kaufert JM, Koolage WW (1984) Role conflict among 'culture brokers': the experience of native Canadian medical interpreters. Soc Sci Med 18:283-286.

Kaufert JM, Putsch RW (1997) Communication through interpreters in healthcare: Ethical dilemmas arising from differences in class, culture, language, and power. J Clin Ethics 8.

Kleinman A (1978) Concepts and a model for the comparison of medical systems as cultural systems. Soc Sci Med 12:85-95.

Kleinman A, Eisenberg L, Good B (1978) Culture, illness, and care: clinical lessons from anthropologic and cross-cultural research. Ann Intern Med 88:251-258.

Weiss R (2003) Macht Migration krank? Eine transdisziplinäre Analyse der Gesundheit von Migrantinnen und Migranten. Zürich: Seismo. 